\title{
Innovation of the Process of Inventorying of the Selected Transport Units: Case Study in the Automotive Industry
}

\author{
Jan Chocholáč ${ }^{*}$, Ladislava Boháčová ${ }^{1}$, Tomáš Kučera ${ }^{1}$ and Dana Sommerauerová ${ }^{1}$ \\ ${ }^{1}$ University of Pardubice, Department of Transport Management, Marketing and Logistics, \\ Studentská 95, Pardubice, Czech Republic; Email: jan.chocholac@upce.cz, \\ ladislava.bohacova@student.upce.cz,tomas.kucera@student.upce.cz, \\ dana.sommerauerova@student.upce.cz
}

*Corresponding Author: Jan Chocholáč

\begin{abstract}
In the current situation, highly competitive time when the emphasis is on shortening delivery schedules, streamlining the production cycle and, ultimately, reducing the total cost businesses are forced to optimizations and innovations. The article deals with the inventory of the selected transport units in warehouses. The inventory is currently being carried out through manual labor of employees. This paper proposes a possible implementation of new and innovative approach to inventory control, with the help of an automated inventory realized by the drones.
\end{abstract}

Keywords: inventorying, transport units, automotive industry, logistic chain

\section{Introduction}

Each company tries to find a way to increase their competitiveness and to be effective, so it is important to monitor the development of modern technologies and trends that provide a significant advantage in a saturated global logistic market.

In companies engaged in the production of goods include warehouse management very important elements of the supply chain, since the holding of stocks in any form of warehouse is essential. It is very important that the process of warehousing and stocks were steady improvement, while maintaining the lowest possible cost. Management of material flow is for the total logistic process very important. In recent decades, many companies seek to streamline operations carried out within the inventory of stocks to minimize errors, cut costs and gain a competitive advantage over other companies in the industry.

\subsection{Literature Review}


The term "logistic chain" is in the logistic theory very widespread and this term is among the most important logistic terms.

Stehlík and Kapoun [1] defined logistic chain as a dynamic connection between customer markets and markets with raw materials, semi-finished products components and materials. This definition also confirmed. Each logistic chain has two important aspects which coexist with each other. The first aspect is tangible part and the second aspect is intangible part of the logistic chain. These links are expedient between demands from final customers, which are connecting with concrete contract, product and raw material [2]. Logistic chains of the automotive industry have some specific aspects which companies must cogitate when they make some decisions [3, 4].

\subsection{Material Flow in the Logistics Chain}

The resulting effect of the logistic solutions is customer satisfaction; usually it is about customer's material needs.

Stehlík and Kapoun [1] defined material flow as a movement of materials in the manufacturing process or under circulation, which is done by handling means, transport means and auxiliary means and devices purposefully with one crucial aim - material must be available at a given location, in the required amount, in the required time and with a predetermined reliability.

Firstly, suppliers deliver materials which are need to manufacturing of products. These materials are located to warehouse, then materials are picked up to appropriate production, where are materials consumed. At the end of the production are products stored to the warehouse of final products. The last phase is distribution of products to final customers. It is related with the selected distribution method [5].

\subsection{Inventorying and Inventory Process}

Inventory is a process of finding real state of properties and liabilities for a certain day according to individual items (for example inventory of goods to 31. 12.). Inventorying is a complex of activities which are directly connect with preparation of inventory, realization of inventory and evaluation of inventory. Inventorying includes finding of real state of properties and liabilities by inventory, preparation of inventory lists and inventory differences, analysing of causes of inventory differences and preparing some proposals for settlement of these differences for management of accounting entity [6].

Inventory process is governed by Accounting Act as amended. Accounting entities take stock to date when accounting units compile financial statements (proper financial statements 
or extraordinary financial statements). Nowadays there are cases when accounting entities take stock during the reporting period which is known as perpetual inventories [7].

Schiffer [8] stated that inventory process helps ensure accordance of types of property and state of liabilities with accounting records. This accordance should be necessary monitored at each balance sheet and off-balance sheet account. Inventory process is more difficult in relation to company's size.

Physical inventory is carried out on the property where is possible find out its existence visually. Real state of property is carried out by counting, measuring, weighing or other similar methods, or may be used accounting records that prove the existence of company's property [7].

In cases when accounting entities commonly use immovable property or accounting entities may prove the existence of immovable property by photographic or similar documentation, there is not necessary to verify its existence visually [9].

The basic distribution of inventory is on complete inventory and partial inventory. The subject of complete inventory is all components of properties and commitments. Partial inventory is focused on selected components of properties and commitments [10].

Holíková [10] described further distribution of inventory, not only according to the range of the inventory (complete and partial inventory). Author divided inventories by time on ordinary and extraordinary inventories.

Annual financial statements are compiled by accounting entities to the last day of accounting period and it is the case of the ordinary inventory. In case of accounting entities compiled annual financial statements another day than the last day of accounting period that is an extraordinary inventory. There are some examples when accounting entities use extraordinary inventory: setting up a business, its mergers, divisions, after a natural disaster or burglary. Ordinary inventory is further subdivided on routine inventory and periodic inventory [10].

Accounting entities use periodic inventory in case when compile annual financial statements. Accounting entities take stock gradually during the reporting period. Routine inventory can be performed only on stocks for which accounting entities charged by species or places to store them, and for tangible movable property which is in constant motion and does not permanent place where they belong [7].

\section{Data And Methods}

This analysis was processed for the selected transport units (pallets) in the company which is focused on the automotive industry. 
Suppliers supply the number of components according to references. Components are transported most often in crates on pallets. Pallets with components are taken over to the central warehouse, whence are transported with the use of conveyors and conveyor bridges to the supermarket. Components are sequenced in the supermarket according to requests from assembly. Auto-trucks transport components to assembly lines then empty transport units (pallets) are taken away to the warehouse of transport units. This company processes three types of inventories, there are: daily inventory, extraordinary inventory and annual inventory.

Daily inventory is realized for transport units every morning at 6 a.m. Extraordinary inventory is realized for selected transport units anytime of the year according to company's or supplier's needs. Annual inventory is realized once a year, but this type of inventory is massive and it has a crucial importance for company. Analysed company has own information system where are registered all information about transport units and operations with these transport units, for example income, picking or restoring within the company.

\subsection{Daily Inventory}

Daily inventory of empty transport units is processed every day. Transport units are divided into two basic groups: transport units with slow circulation and transport units with fast circulation. Transport units with slow circulation are inventoried every morning, but transport units with fast circulation are inventoried three times per day when employees finish their shift. Daily inventory is processed in all warehouses of the company, where are transport units stored. Daily inventory has important advantage, because it does not disrupt production fluency.

Selected employee must execute inventory of empty transport units. Employee must print a form for inventory. This form consists of kinds of transport units and their quantities. Then employee goes through the warehouse of transport units and counts all empty transport units on every location. Employee must differentiate types of transport units and their amounts. In conclusion employee enters calculated data into the company information system.

Daily morning inventory takes approximately 90 minutes, daily afternoon and daily night inventory take approximately 45 minutes. Total time of daily inventory is about 3 hours. Error rate of counting of employee is about $3 \%$.

Pallets with fast circulation are inventoried three times a day. Their amount must be minimized, because company rents these transport units. Pallets are relocated several times per day, but due to inventory company has accurate information about their amount and location.

\subsection{Extraordinary Inventory}


Extraordinary inventory is processed in the situation when supplier does not have enough empty transport units for components and analysed company does not have information about these transport units in own information system. Extraordinary inventory is processed during operation.

\subsection{Annual Inventory}

Annual inventory is supported by accounting act. Analysed company processes annual inventory once a year. It is a special day when is prohibited to move or transfer some components, materials, raw materials, semi-finished products, finished products and transport units. There are some exceptions for catering, integrated rescue systems etc.

Inventory is processed manually. Each transport unit is marked with a unique number. Each warehouse is split into areas and racks. Each rack is divided into columns and each warehouse areas are divided into smaller sections. All measures are for greater clarity. Employee who processes the inventory has a form with types of transport units and registers amount of each type of transport units. Finally, employee lays the form on the relevant section. Then internal commission verifies employee's form. Internal commission converts amount of transport units in the section and compares them with data in the form. In the end employee manually enters data about types and amount to the company's information system.

\subsection{Innovation of the Process of Inventorying of the Selected Transport Units}

Current method of the process of inventorying of the selected transport units has several problems which cause inefficiency. Used procedure is time-consuming, inaccurate and expensive.

Propose of the innovation is based on the use of drone "Kingfisher" for inventorying of the transport units (pallets). This drone is universal hexacopter with load capacity $5 \mathrm{~kg}$. Kingfisher can fly for 45 minutes with maximal speed about $70 \mathrm{~km} / \mathrm{h}$. Data are transferred digitally at distances up to $3 \mathrm{~km}$ [11-13].

The basis of the Kingfisher's control system is flight unit that contains gyroscopes, accelerometer, compass (GPS) and pressure gauge (altimeter). Drone will be equipped by infrared lasers which help with orientation in the terrain with the use of LiDAR method. LiDAR is a method of remote measurement of distance by calculating the propagation time pulse of the laser beam reflected from the subject that can be easily applied for terrain mapping and measuring distances. The result of LiDAR method is a digital terrain model, for example roads, buildings, natural vegetation or stack of pallets. The diagram of the innovation inventory process using "Kingfisher" is in Fig. 1. 


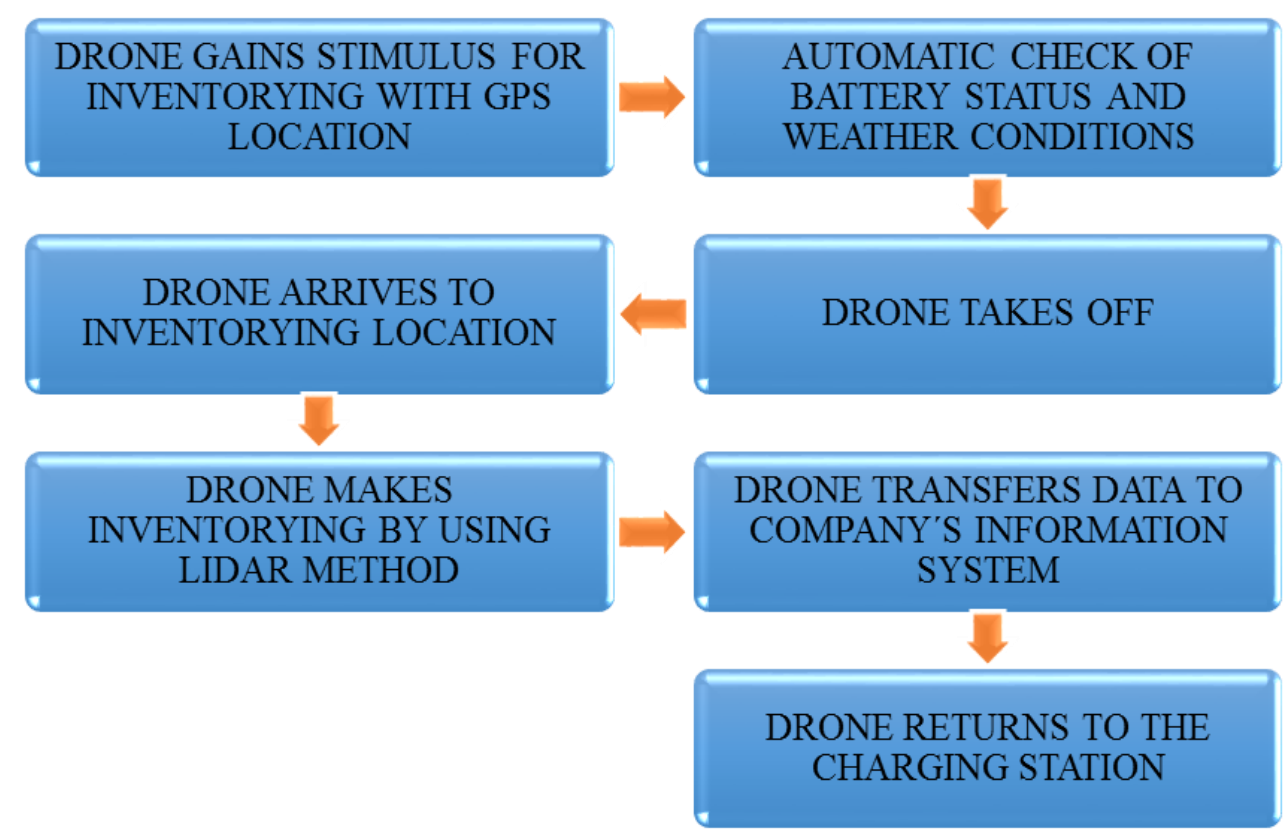

Fig. 1 Diagram of the daily inventory. Source: [authors]

Firstly, drone must obtain stimulus to inventory process. It is possible to set up regularly three times a day for processing of daily inventory. Then drone activates itself and takes off. Drone flies by GPS to the place of inventory where he makes inventory of transport units using LiDAR method. Then drone transfers data to company's information system.

\section{Results and Discussion}

Innovation of the process of inventorying of the selected transport units has these advantages (see Tab. 1): reducing number of employees from 3 to 0 , because drone will realize the inventory automatically; reducing inventory time from 3 hours by employees to 1 hour by drone (per day) and reducing error rate from $3 \%$ to $0.5 \%$.

Table 1 Comparison between current state and state after innovation. Source: [authors]

\begin{tabular}{ccc}
\hline & Current state & State after innovation \\
\hline Number of employees & 3 & 0 \\
\hline Execution inventory time & 3 hours a day (employees) & 1 hour a day (drone) \\
\hline Error rate & $3 \%$ & $0.5 \%$ \\
\hline
\end{tabular}

The article dealt with the innovation of the process of inventorying of the selected transport units as a case study in the automotive industry. The article specifically described material flow and related means of transport, from receiving materials to the central warehouse through a conveyor 
bridge, supermarket, assembly line until the store empties. Furthermore, the process is analysed daily, extraordinary and annual inventory of the selected transport units.

The article is also dedicated to finding inefficient, manual process of performing an inventory of the selected transport units and designed an innovative process inventory means of transportation through the drone Kingfisher, which is equipped with special software and equipment. This article also provides a comparison of the current situation and possible uses of the drone as an innovative solution to the inventory of the selected transport units. The benefit is to reduce the error rate from $3 \%$ to $0.5 \%$, reduce number of employees from 3 to 0 people and reduce inventory of the execution time from 3 hours to 1 hour a day by the drone.

\section{Conclusion}

Each company tries to improve continuously its processes, reduce costs, use innovative technologies, increase the accuracy of operations and reduce error rate of operations. Innovation of the process of inventorying of the selected transport units by using drone "Kingfisher" for inventorying pallets is innovative approach of the inventory process. The benefit is to reduce the error rate, reduce number of employees and reduce execution time of the inventory. Drones may be used in the future not only for inventorying pallets, but it may be used for inventorying other transport units, some raw materials, components, materials, semi-finished or finished products.

\section{Acknowledgments}

This article is published within the solution of project no. SGS_2017_009 „Traffic Engineering, Technology and Management”.

\section{References}

[1] Stehlík, A. \& Kapoun, J. (2008). Logistics for Managers. Praha: Ekopress. ISBN 978-80-86929-37-8.

[2] Cooper, M.C., Lambert, D.M. \& Pagh, J.D. (1997). Supply chain management: more than a new name for logistics. The International Journal of Logistics Management, 8(1), 1-13. DOI: $10.1108 / 09574099710805556$.

[3] Doernhoefer, M. \& Guenthner, W.A. (2017). A research and industry perspective on automotive logistics performance measurement. International Journal of Logistics Management, 28(1), 102-126. DOI: 10.1108/IJLM-06-2015-0105. 
[4] Skerlic, S. \& Muha, R. (2016). The importance of systems for controlling logistics costs in the supply chain: a case study from the Slovenian automotive industry. Promet-Traffic \& Transportation, 28(3), 299-310. DOI: 10.7307/ptt.v28i3.1881.

[5] Lummus, R.R., Krumwiede, D.W. \& Vokurka, R.J. (2001). The relationship of logistics to supply chain management: developing a common industry definition. Industrial Management \& Data Systems, 101(8-9), 426-431. DOI: 10.1108/02635570110406730.

[6] Svobodová, J. (2011). Inventory - a practical guide. Olomouc: ANAG. ISBN 978-80-7263-783-6.

[7] Česko. (2017). Accounting act no. 563/1991. Retrieved March 10, 2017, from http://www.zakonyprolidi.cz/cs/1991-563/zneni-20160919.

[8] Schiffer, V. (2006). Inventory in Practice - Questions and Answers. Praha: Grada. ISBN 80-2471-921-5.

[9] Česko. (2017). Notice no. 270/2010. Retrieved March 10, 2017, from http://www.zakonyprolidi.cz/cs/2010-270/zneni-20160101.

[10] Holíková, P. (2016). Inventory. Retrived March 2, 2017, from https://www.uctovani.net/clanek.php?t=Inventarizace\&idc=32.

[11] Bošnak, M., Matko, D. \& Blažič, S. (2012). Quadrocopter hovering using position-estimation information from inertial sensors and a high-delay video system. Journal of Intelligent \& Robotic Systems, 67(1), 43-60. DOI: 10.1007/s10846-011-9646-5.

[12] Harik, E.H.Ch. (2016). Towards an Autonomous Warehouse Inventory Scheme. 2016 IEEE Symposium Series on Computational Intelligence. DOI: 10.1109/SSCI.2016.7850056.

[13] Robodrone. (2016). Robodrone - drones. Retrieved March 15, 2017, from http://www.robodrone.com/drony. 